Letrônica, Porto Alegre, v. 7, n. 2, p. 904-916, jul./dez., 2014

\title{
DIÁRIOS DE VIAGEM COMO DISCURSO: O ENCONTRO DE P.K. PAGE COM O BRASIL DA PRIMEIRA METADE DO SÉCULO XX
}

\author{
TRAVEL DIARIES AS DISCOURSE: \\ P.K. PAGE'S ENCOUNTER WITH MID-TWENTIENTH CENTURY BRAZIL
}

Maria das Graças Salgado*

\begin{abstract}
Resumo: De um modo geral, os diários de viagem oferecem importante via de acesso à singularidade da experiência do viajante e de suas reações mais pessoais à nova sociedade em que busca ser inserido. Todavia, percebidos em sua dimensão discursiva, os diários representam também uma poderosa via de compreensão do periodo e da cultura dessa nova sociedade. $\mathrm{O}$ objetivo deste trabalho é discutir alguns aspectos associados ao olhar de $\mathrm{P}$. K. Page sobre o Brasil da primeira metade do século XX. Perguntamo-nos, por exemplo: como Page via os hábitos e costumes locais da época? Como foi sua relação com a língua portuguesa durante o processo de adaptação? Quais foram suas impressões sobre a vida cotidiana no Rio de Janeiro? Que impacto teve a administração da vida doméstica em sua experiência de viajante? Para tanto, nos apoiamos na ideia de diários como discurso historicamente situado, tomando como material de análise o livro da autora Brazilian Journal (1987). Resultados indicam que, embora gostasse sinceramente do Brazil, a autora faz importante crítica social, muitas vezes apegada ao recurso da ironia em suas descrições do cotidiano e da administração da vida doméstica.
\end{abstract}

Palavras-chave: P. K. Page; Diários de viagem; Discurso; Século XX.

\begin{abstract}
On a general level, travel diaries offer an important way to access the singularity of travellers' subjective experience and their reaction to the new society in which they intend to live. However, viewed as discourse, travel diaries also represent a tool which reveals sociocultural aspects of the new society itself. This paper aims to discuss aspects associated to P. K. Page's view of mid-nineteenth Century Brazil. Thus, important questions arise, such as: how did Page view the local habits and customs of the time? What was her relationship with the Portuguese language during her process of adaptation? What were her impressions about Rio de Janeiro's daily life? What impact did the household management have in her travel experience? To this purpose, the paper adopts the idea of travel diaries as historically situated discourse, taking Page's Brazilian Journal (1987) as material for analysis. Results
\end{abstract}

\footnotetext{
${ }^{*}$ Doutora em Letras pela PUC-RJ, professora adjunta de Inglês da Universidade Federal Rural do Rio de Janeiro (UFRRJ). Tradutora do inglês para o português, tendo traduzido, em parceria com o historiador Eduardo Silva (FCRB), o livro Stefan and Lotte Zweig's South American Letters: New York, Argentina and Brazil, 1940-42 (Tradução para o português: Rio de Janeiro, Versal, 2012). Desenvolve pesquisas no campo da análise crítica do discurso e tem publicado artigos sobre representações sociais de gênero, memória e emoção. Atualmente desenvolve projetos de pesquisa que exploram a relação entre gênero, memória e emoção em narrativas autobiográficas em inglês e português. É líder do grupo de pesquisa GEDIR: Gênero, Discurso e Imagem (CNPq/UFRRJ). E-mail: salgado@ufrri.br
} 
indicate that, although Page sincerely loved Brazil, she also made important social criticism of the country, very often through irony in her descriptions of daily life and the Brazilian management of domestic life.

Keywords: P. K. Page; Travel diaries; Discourse; Twentieth century.

\begin{abstract}
Perturbada e excitada com o Brasil. Por quê? 0 que significa tudo isso? O lugar altera a pessoa? É como ficar apaixonada - pelo próprio país (PAGE, 1987, p.46).

Eles são tão calorosos - os brasileiros - eles lhe tocam, lhe bajulam, lhe beijam, lhe amam. E, claro, lhe esquecem no dia seguinte. [...] Acho que eu poderia gostar da maioria das pessoas realmente gostar delas - se eu sentisse que jamais teria de vê-las de novo (PAGE, 1987, p. 70).
\end{abstract}

\title{
Introdução
}

Patricia Kathleen Page, ou P.K. Page (1916-2010), foi uma escritora britânica que, por circunstâncias pessoais, mudou-se aos três anos de idade para Calgary, Canadá, e acabou sendo identificada como poeta canadense pelo resto de sua vida. Casada com o embaixador Arthur Irwin, portanto, familiarizada com viagens e mudanças de países, Page estava confortavelmente instalada em Lae (Nova Guiné), quando, em 1956, ouviu do marido a notícia de que teriam de se mudar para o Brasil. Completamente integrada e ainda embevecida com a natureza tropical da Nova Guiné, reagiu à notícia com incredulidade e total desprezo. Chegou a atribuir tal reação à desagradável lembrança associada às esposas diplomáticas latino-americanas que havia conhecido em seu país. Aos poucos, todavia, essa primeira reação foi sendo substituída pela agradável lembrança de que no Brasil encontraria, e com muito mais abundância, tudo aquilo que amava na Nova Guiné: o clima tropical, a vegetação, o calor e mais, muito mais (PAGE, 1987, p. 1-2).

Essa tomada de consciência muda completamente o estado de espírito da escritora, que passa a ver o novo destino de forma muito mais animadora, como teremos oportunidade de ver mais adiante, na análise dos dados baseada no diário brasileiro da escritora.

De um modo geral, podemos dizer que os diários de viagem oferecem importante via de acesso à especificidade ou singularidade da experiência do viajante e suas reações 
mais pessoais à nova sociedade em que pretende se inserir. Todavia, percebidos em sua dimensão discursiva, representam também uma poderosa via de acesso ao período e à cultura dessa nova sociedade, pela ótica do viajante. Explorando o elemento autobiográfico dos diários de viagem enquanto discurso historicamente situado, o objetivo deste trabalho é analisar alguns aspectos do discurso de P.K. Page sobre o Brasil da primeira metade do século XX, a partir do registro de sua experiência de viajante no país, no final dos anos 1950. Nessa direção, algumas questões parecem fundamentais: (i) como Page via os hábitos e costumes locais da época? (ii) que relação estabeleceu com a língua portuguesa durante o processo de adaptação? (iii) que impressões guardou sobre a vida cotidiana no Rio de Janeiro? (iv) como percebia a administração da vida doméstica durante o tempo em que viveu no Brasil?

Tomamos como material de análise o livro Brazilian Journal (1987), escrito por Page (trinta anos depois de ter deixado o Brasil), a partir de suas anotações pessoais em diário e da correspondência mantida com amigos e familiares. Neste trabalho, o recorte mais específico é feito com base em dois eixos considerados relevantes para a análise: (i) a relação da escritora com a língua estrangeira, neste caso, o português; e (ii) o gerenciamento da vida doméstica, sobretudo sua interlocução com os empregados.

Os dados sugerem que, embora tenha se apaixonado pelo Brasil, P.K. Page faz importante crítica social ao país, muitas vezes apegada ao recurso da ironia, como mostra a epígrafe de abertura do trabalho. Esse discurso é particularmente perceptível em suas descrições sobre o funcionamento da vida doméstica na residência oficial onde vivia com o marido, no Rio de Janeiro. Para Page, a casa, e sua intrincada rede de relações, representa, em certa medida, um microcosmo da própria sociedade brasileira da primeira metade do século XX.

Para melhor desenvolvimento da análise, começamos por salientar a importância do componente autobiográfico dos diários pessoais, chamando a atenção para o conceito de autobiografia em duas perspectivas: (i) como espaço discursivo, cujo gênero é tipicamente marcado pelo caráter do hibridismo (MARCUS, 2006), contemplando, assim, um diálogo próximo com o diário de viagem; e (ii) como testemunho social, ou seja, discurso fundamentado na reconstrução da memória para falar da e sobre a própria vida e a vida do outro (FELMAN; LAUB, 1992), como é o caso de K.P. Page, no lugar de viajante testemunhando o Brasil prestes a ingressar na histórica década de 1960. 
Cabe dizer que até o momento não há tradução para o português do diário em questão. As traduções do inglês para o português neste trabalho são de nossa responsabilidade.

\section{Discursos autobiográficos}

Os estudos sobre autobiografia na modernidade ocidental foram marcados pela publicação do seminal texto de Phillippe Lejeune (1971) sobre o pacto autobiográfico enquanto narrativa contada por uma pessoa real comprometida com a verdade dos fatos a partir da assinatura do nome próprio no título da capa. Ali, o autor pretende delimitar as fronteiras e características da autobiografia como um gênero particular ancorado em referências localizadas além do texto. Essas referências dizem respeito a um mundo pertencente a uma pessoa real, cuja marca mais verificável é a assinatura do nome próprio.

As reações positivas e negativas a essa proposição teórica ajudaram a consolidar a autobiografia como disciplina autônoma. Com isso, outras ciências, como a historiografia (particularmente a história oral), a antropologia, a educação, a linguística e a teoria literária se aproximam dos estudos autobiográficos, estabelecendo um diálogo que vem reafirmando cada vez mais o interesse pela chamada escrita de si, a qual abraça vários gêneros, inclusive o diário pessoal.

De acordo com Marcus (2006, p.2), esse quadro favorável à escrita da própria vida teve a contribuição definitiva da crítica feminista, da historiografia negra e dos movimentos sociais das classes trabalhadoras. Sob os efeitos desses movimentos, a produção autobiográfica passa a ser, nos anos 1980, uma maneira de expor os processos de exclusão na construção do cânone literário, mostrando que a tradição autobiográfica pertencia aos chamados 'grandes homens', excluindo as mulheres e determinadas formas de escrita da vida geralmente adotadas por mulheres, como cartas e diários.

A partir dos movimentos liderados pela crítica feminista, percebe-se que recontar a própria vida e história necessariamente implica a escrita de outro ou outros. Da mesma maneira, escrever a vida de outro implica uma identificação, explícita ou não, do biógrafo com o seu objeto (MARCUS, 2006, p. 273). Seja como for, a autobiografia, como gênero, propicia discussões fundamentais para os estudos discursivos em geral e para o 
discurso literário, em particular. A tradicional divisão entre fato e ficção, as noções de autoria e sujeito e, sobretudo, o conceito de testemunho como prática discursiva são apenas alguns exemplos que mostram a importância da autobiografia para o desenvolvimento dos estudos linguísticos, literários, culturais, históricos, entre outros.

No tocante à autobiografia como testemunho, Felman e Laub (1992) privilegiam o papel da linguagem em situação de uso e abordam o testemunho como uma linguagem em curso, que ainda não alcançou entendimento conclusivo. Composto de fragmentos da lembrança inundada por episódios e ocorrências, o testemunho não oferece um relato completo dos eventos, tratando-se, assim, de uma prática discursiva que produz significado a partir de sua recepção (FELMAN; LAUB, 1992, p.5).

A narrativa de viagem de P.K. Page, descrita por meio de seu diário pessoal e de sua correnpondência, é uma narrativa autobiográfica, cujo recorte temporal e geográfico se insere no Brasil - mais especificamente no Rio de Janeiro -, durante os anos de 1957 a 1959. Em sua dimensão discursiva, contudo, representa também um depoimento sobre o tempo e o contexto histórico e sociocultural que testemunhou. É, portanto, um testemunho no qual a escritora fala não apenas de si, mas de toda uma complexa rede de relações envolvida em seu cotidiano de viajante ilustre que reflete um contexto sociocultural mais amplo.

\section{A nova língua}

Parece natural que a primeira preocupação de qualquer viajante com destino a um país estrangeiro seja o aprendizado da nova língua. É fundamentalmente por meio da língua que conduzirá seu processo mais amplo de adaptação à nova sociedade. Caso incomum, observado em outro trabalho (SILVA; SALGADO, 2014), no entanto, diz respeito à experiência linguística do escritor austríaco Stefan Zweig e sua jovem esposa Lotte Zweig. Ao fugirem da perseguição aos judeus durante a Segunda Guerra, eles escolhem o Brasil como abrigo e, embora tenham amado o país, surpreendentemente, os Zweig demonstravam não apenas total desinteresse, como rejeição, ao nosso velho português, língua do país que o próprio escritor percebia como "um país do futuro". 1

\footnotetext{
${ }^{1}$ Informações mais detalhadas podem ser encontradas em "O que há de errado com o português? 0 processo de adaptação linguística de Stefan e Lotte Zweig no país do futuro", artigo de autoria de Eduardo Silva (FCRB) e Maria das Graças Salgado (UFRRJ), que foi apresentado no XIII Congresso da BRASA, em
} 
É claro que estamos falando de situações completamente diferentes, visto que o drama do casal Zweig está inserido em um contexto de exílio forçado, que os obriga também a abandonar a própria língua. Diferentemente, Page vive um contexto de mudança de país, tão somente em função das obrigações diplomáticas do marido. De todo modo, em ambos os casos temos um quadro mais amplo que está associado à abertura cultural e predisposição interna dos indivíduos à aprendizagem de uma nova língua e de uma nova cultura. Como europeus cultos, os Zweig falavam várias línguas. Seria natural, portanto, que estivessem dispostos a aprender exatamente a língua do país que os abrigaria na condição de refugiados, o que não aconteceu. Diferentemente desse quadro de resistência à nova língua, P.K. Page, que aparentemente não falava línguas estrangeiras, foi uma viajante muito preocupada com o tópico, destacando sempre a presença e importância do português para o correr da vida no Brasil. Já no que chama de foretaste de seu Brazilian Journal, a escritora mostra as preocupações do casal em aprender ao menos alguma coisa do português, antes da partida para o Brasil.

Durante as semanas que antecederam nós havíamos tentado, sem muito sucesso, [...] aprender os rudimentos do português [...] Eu já me perguntava se conseguiria dominar a língua - eu que nunca havia dominado adequadamente o francês. (PAGE, 1987, p. 1-2).

Chegando ao Brasil e, uma vez estabelecidos na residência oficial do casal, no Rio de Janeiro, Page se convence cada vez mais da relevância da língua no tocante ao funcionamento da casa que, além de casa da família, era palco também de constantes reuniões voltadas para tomadas de decisões diplomáticas e políticas. Em carta de 17 de março de 1957, destaca o completo sentimento de fragilidade decorrente da falta de domínio do portugês.

Quão inútil alguém se torna pela falta de uma língua! Eu não apenas falo como um bebê, com um sotaque horrível, mas as coisas que eu realmente digo são muito frequentemente diferentes daquilo que eu queria dizer. Isso confunde os empregados sem parar. Eu dou algumas ordens, e eles dizem sim, sim, sim. E eu me sinto ótima, no controle de tudo, por cima da carne seca. Depois, nada

Londres, em agosto de 2014. Espera-se que o artigo seja publicado posteriormente pela BRASA (20142015). 
acontece. (PAGE, 1987, p. 26-7).

Essa aparente sensação de desamparo causada pelo desconhecimento do português, contudo, não prejudica as primeiras impressões positivas sobre o Rio de Janeiro. Evelyn concorda de imediato com os elogios que ouvira acerca da beleza da cidade. Sem a menor sombra de dúvida, o Rio lhe pareceu uma espécie de paraíso tropical, em nada devendo à Nova Guiné que tanto amava. Mas, apesar desse sentimento positivo, nos primeiros dias, quase não aproveitara a exuberante ambiência, pois além de tantas tarefas iniciais, ela se dedicava à aprendizagem da língua local: "pouco fiz desde que chegamos, a não ser desempacotar, inspecionar e tentar fazer as coisas funcionarem. E estudar português" (PAGE, 1987, p. 8).

Além de totalmente consciente da relevância da língua como meio de comunicação, inclusive corporal, Page demonstra também curiosidade pelo próprio sistema linguístico do idioma, mas não deixa de criticar, com certa dose de ironia, alguns aspectos da mentalidade e cultura brasileira. O português é fascinante. Em um país que, para nós, parece dar pouco valor à
vida, há pouca diferença entre as palavras "viver", morar, e morrer. Até o
momento eu não tive capacidade de encontrar qualquer expressão para "que
engraçado", - talvez porque os brasileiros achem tudo engraçado. A gente
aprende muito bom [...] imediatamente; é usado para se falar de praticamente
tudo que não está muito bem, ou muito mau. E o ubíquo muito é falado com tanta
emoção, que até os eventos mais comuns tornam-se dramáticos. (PAGE, 1987,
p.30).

As descrições de Page revelam, portanto, não apenas interesse real pelo novo idioma, tanto no seu aspecto instrumental de uso, como linguístico, mas também grande senso de observação da nova ordem social em que estava inserida. É nesse esquema mental de curiosidade e sentido de observação que Page comenta, por exemplo, as diferenças de uso da língua, a partir do canal utilizado, e as peculiares diferenças de formas de endereçamento do português.

Interessantes as diferenças entre linguagem textual e linguagem falada. Serviçais não são mais criados - uma palavra originada da escravidão, quando uma criança pequena era trazida para a casa grande e, com efeito, "criada" ali - mas empregados. Mas ao mesmo tempo os empregados ainda são endereçados como você, a segunda pessoa, como uma criança ou uma pessoa íntima seriam 
tratadas, não como o senhor ou a senhora, a mais formal terceira pessoa. (PAGE, 1987, p. 30).

É evidente que, aqui, Page tem como referência sua própria cultura, onde um empregado é normalmente tratado como Senhor ou Senhora, não necessariamente por uma questão apenas de respeito, mas como uma forma de marcar a distância social entre indíduos ocupando papéis sociais desiguais.

Por ocasião de sua primeira visita oficial, quando Page e a amiga Henrietta foram recebidas pela esposa de um titular do Gabinete da embaixada canadense, a escritora observa a casa e a ambiência social com muito detalhe, e faz questão de explicitar particular reserva ao ritual de despedida:

Quando eu apertei suas mãos, nossa anfitriã me deu o tipo de puxão que precede um beijo. Despreparada, minha mente rejeitou a possibilidade e meu corpo o puxão. Com Henrietta, que também não a conhecia, mas era velha conhecida dos modos brasileiros, o beijo foi trocado. Isso também é línguagem. [...] (PAGE, 1987, p.30)

Novamente, Page está contrapondo dados culturais do Brasil com aqueles de seu país de origem, onde a aproximação física entre estranhos não é nem realizada com frequência, nem desejada.

Observa-se, portanto, que o envolvimento de Page com a questão da língua, de fato, ultrapassa a fronteira das situações domésticas prejudicadas pela falta de domínio do português. Durante sua primeira visita oficial a São Paulo, por exemplo, Page e o Embaixador Arthur Irwin visitam uma escola dirigida por religiosos canadenses, onde a escritora faz questão de destacar a importância da ocasião. Além de valorizar a ocasião porque o marido proferiria seus primeiros discursos em português, Page se mostra extremamente atenta às sutilezas da língua no cancioneiro popular.

No primeiro dia nós fomos ver a escola dirigida pelos Padres Canadenses da Santa Cruz. Eu fui presenteada com um enorme buquê de flores por uma criança minúscula, e A. fez seu primeiro discurso em português. As crianças cantaram "Oh Canadá" e "Alouette" - Gentee Alouettee soou muito engraçado. Para o final, duas criaturinhas sambaram ao som do sucesso do carnaval daquele ano, "Eu vou". É uma canção deliciosa sobre um homem que está decidido a ir para Maracangalha, venha o que vier. Se Anália não quiser ir, eu vou só. "Quiser", se desejar - o futuro condicional em uma canção popular! (PAGE, 1987, p.42).

O interesse de Page pela nova língua é amplo a ponto de conduzi-la também por instâncias culturais mais sutis reveladas pela língua, como o complicado contexto das 
piadas, charadas e expressões idiomáticas.

\begin{abstract}
Existe uma frase usada aqui - amigo da onça, [...] significando alguém que não é seu amigo. Ouvi sobre sua origem hoje. Um homem disse para outro, "o que você faria se fosse perseguido por uma onça?" "Por quê? Eu correria, é claro." "E se a onça fosse para cima de você?" "Por quê? Eu subiria em uma árvore." "E se a onça subisse na árvore atrás de você?" "Escuta aqui, quem é você, afinal de contas? Você é meu amigo ou amigo da onça?" (PAGE, 1987, p.59).
\end{abstract}

Ainda nessa mesma visita a São Paulo, Page continua orgulhosa do desempenho linguístico do marido, fazendo questão de contrapor sua abertura cultural à falta de boa vontade e abertura de alguns embaixadores de outras nacionalidades no processo de integração ao país.

No dia seguinte A. fez três discursos em português - o primeiro, na Câmara dos Deputados. Me disseram que havia muitos deputados nos corredores quando ele começou e alguns na Câmara estavam conversando ou lendo, mas quando ouviram português, aqueles nos corredores voltaram para ouvir o discurso. $\mathrm{O}$ adido falou que recentemente existiram quatro embaixadores por aqui, e que $\mathrm{A}$. foi o único a usar o português. 0 japonês falou em japonês! (PAGE, 1987, p.42).

O esforço da escritora em aprender o português inclui também a atividade da leitura, a qual nem sempre levava adiante.

Estou lendo um romance de Daphne du Maurier em português. Eu consigo me virar com a ajuda do dicionário, mas isso me entedia. 0 problema é o seguinte: 0 que me interessa eu não consigo ler; o que eu consigo ler, não me interessa (PAGE, 1987, p. 55).

Todavia, essa difícil equação não a desencoraja de ler sobre o pintor que mais admirou no Brasil, fazendo belíssima descrição sobre o mesmo.

Estou lutando para ler um livro sobre Portinari em Português - mais dificil do que o livro de Du Maurier, que o tédio me forçou a abandonar, e mais interessante. Que homem extraordinário! [...] Suas pinturas e desenhos de crianças brincando em Brodowski são infinitamente mais comoventes do que os grandes painéis representando o sofrimento de trabalhadores. Aquelas criancinhas correndo na vastidão do espaço, espalhadas como grãos, penetram em mim como agulhas (PAGE, 1987, p. 55-56).

Vimos até agora que a escritora P.K. Page teve, de fato, uma relação de encantamento pelo Brasil, a qual, em certa medida, é perceptível pelo empenho e interesse pela língua portuguesa. Contudo, a despeito de todo o encanto e interesse pela nova língua e pelo país, Page exerce também um olhar crítico acerca dos problemas e limitações da nova cultura e sociedade. 


\section{3 "Esta é uma casa muito pública": a complexa rede de relações no universo privado de P.K. Page}

Além de explorar várias questões linguísticas que apontam interesse genuíno pela língua portuguesa, Page dedicou um grande espaço da memória à intrincada e complexa rede de relações estabelecidadas no ambiente doméstico da sociedade brasileira. Nesse sentido, inúmeras páginas do seu Brazilian Journal voltam-se para descrições e comentários sobre os empregados, tanto de sua casa, como de casas que visitava na condição de embaixatriz.

Podemos imaginar que a criadagem envolvida no funcionamento da residência oficial de um embaixador, no Brasil dos anos 1950, tivesse que incluir um complexo contingente de empregados. No caso de Page, esse contingente, embora muito rico em sua diversidade racial, cultural e linguística (cabendo até a possibilidade de empregados poliglotas), tinha suas complicações próprias. Mas ela estava confiante no andamento das coisas.

\footnotetext{
Nós fomos apresentados a uma empregada alemã que fala sete línguas nenhuma delas a minha. Já estou vendo que ela vai ter que ir embora. Além disso, temos um casal espanhol, Guillermo e Maria, que falam um pouco português; um chofer brasileiro, Nildo, que no momento está morando na garagem com esposa e filhos num espaço planejado para quatro empregados; um jardineiro português, Ricardo; [...] um ajudante de jardineiro negro cor de carvão, Manuel; uma cozinheira da Bahia e sua ajudante negra cor de carvão; e uma lavadeira que tem elefantíase. A forma correta de administrar esse lugar, eu espero, acontecerá por si só. (PAGE, 1987, p. 7).
}

E em meio a todas as tentativas de fazer com que a vida doméstica corresse normalmente, mais uma vez a língua surge como um fator relevante.

\footnotetext{
Aí existem as dificuldades de língua. Eu gasto um tempo enorme tentando me comunicar com os empregados e outro tempo quase igual para desenrolar os mal-entendidos que criei. "Não compre mais moças jovens," falo eu para a cozinheira. Horas depois percebo que eu quis dizer maçãs verdes, não moças. (PAGE, 1987, p.13).
}

As dificuldades da língua são muitas e, no nível geral, afetam a todos. No entanto, algumas pessoas são particularmente tocadas por esse elemento de integração social.

Um garoto negro que empregamos como faxineiro ficou tão afetado por minhas dificuldades com o português, que ficou completamente mudo - capaz apenas de gesticular e apontar. No primeiro dia que ele de fato entendeu mesmo alguma 
coisa que eu falei, ele entrou numa espécie de catarse vocal, liberando uma grande inundação de suave fala musical (PAGE, 1987, p.16).

Na verdade, Page parece completamente tomada pela administração da residência oficial, particularmente pela questão dos empregados.

Eu contrato e demito - escrevo recibos em português para os empregados que vão embora assinarem. Eles chegam e vão embora, uma população itinerante, movimentando-se lindamente pela minha casa, minha vida, frequentemente deixando caos atrás deles (PAGE, 1987, p. 16).

A ocupação constante desse papel feminino faz Page lamentar o fato de ter de enfrentar uma rotina que parece não ter outra saída.

Que destino terrível não ter outro interesse ou conversa a não ser empregados. Por enquanto esse parece ser o meu - embora eu tenha jurado solenemente não falar sobre eles a não ser para pedir algum conselho específico. (PAGE, 1987, p.17).

Com o tempo, já mais capacitada para exercer um olhar crítico sobre a nova sociedade, fica evidente para Page que a necessidade de lidar com tantas questões domésticas e a forma como essas questões são conduzidas tem também um componente cultural que ela reprova.

Hoje a casa está cheia de pintores, eletricistas e bombeiros que, em português, significa também pessoal da brigada de incêndio e espiões. [...] Esta é uma casa muito pública - em parte porque estamos atropelados pelos operários, mas isso também tem a ver com a vida brasileira, eu acho. (PAGE, 1987, p. 18).

Ao associar, por meio do recurso irônico, o pessoal da brigada de incêndio a espiões, Page insinua que sua privacidade estava sendo invadida, desvelando a conhecida dificuldade do brasileiro de distinguir o espaço público do privado, como apontam alguns dos nossos clássicos analistas sociais, a exemplo de Sérgio Buarque de Holanda (1983) e Roberto da Matta (1985), para citar apenas estes.

Um componente interessante da complexa rede doméstica que Page tinha de administrar à época revela também um Brasil em que a elite era assistida domesticamente por um número significativo de empregados estrangeiros. Em carta de 2 de março, a escritora parece continuar cansada de contratar e demitir tanta gente, mas não deixa de apreciar a diversidade cultural envolvida naquele processo extenuante.

Uma centena de contratações e demissões. Isso algum dia vai acabar? Nós contratamos um mordomo italiano, Salvador, e sua esposa iugoslava, Mary. Contratamos o beija-mãos russo e sua esposa. [...] A fauna continua interessante. 
(PAGE, 1987, p. 19).

É claro que Page desfrutou bastante aquilo que mais amou no Brasil como um todo e no Rio de Janeiro especificamente: a fauna e a flora. A paisagem, as plantas e os animais não só serviam como fonte de inspiração para suas várias formas de expressão artística, como serviam também para promover um estado de reconciliação com as dificuldades envolvidas no cotidiano doméstico carioca, cujo funcionamento dependia de uma complexa rede de relações, que a escritora nem sempre podia controlar.

[...] Depois de um dos piores dias, domesticamente falando, que já passei em toda minha vida, eu saí para comprar flores para a mesa do jantar e alguma coisa se moveu nos galhos altos das plantas. Eu jurei que perdoaria as aporrinhações do dia inteiro, se aquilo fosse um macaco. E era! Mas a pobre coisinha se balançou para longe de mim e entrou na floresta (PAGE, 1987, p. 20-21).

\section{Conclusão}

Este trabalho se propôs a analisar o discurso da escritora canadense Patricia Kathleen Page, ou P. K. Page, sobre o Brasil, por meio de seu Brazilian Journal, livro que resultou de suas anotações em forma de diário pessoal e da correspondência mantida com amigos e familiares durante os anos vividos no Brasil, de 1957 a 1959.

Propusemos um olhar sobre o diário de viagem de Page, no qual enfatizamos sua natureza discursiva testemunhal e autobiográfica, já que a autora, a partir de um recorte temporal e geográfico abrangendo determinado contexto histórico e sociocultural, conta a própria vida e a vida de outros. Em última instância, portanto, está falando da sociedade que testemunhou.

Tendo sido casada com o embaixador canadense Arthur Irwin, Page era viajante por ofício, e vivia feliz em Lae (Nova Guiné) quando, em 1956, ouviu do marido a notícia de que teriam de se mudar para o Brasil. A primeira reação foi de resistência, na melhor das hipóteses. Aos poucos, todavia, o Brasil foi se configurando como uma grande fonte de inspiração, confirmada posteriormente por grande parte de sua obra artística, sobretudo no tocante à poesia e à pintura. É natural, portanto, que a escritora tenha amado o Brasil verdadeiramente. Todavia, a análise demonstrou que seu olhar sobre a nova cultura e sociedade também foi crítico, sendo, em grande parte, discursivamente expresso por meio da ironia. 
Explorando o elemento autobiográfico dos diários de viagem como discurso historicamente situado, diferentes questões sugiram como fundamentais. Todavia, despertou atenção especial o papel da língua portuguesa durante o processo de adaptação de P. K. Page e o impacto da administração da vida doméstica em sua experiência de viajante. Percebe-se que Page demonstra grande envolvimento com a aprendizagem do idioma local, o que indica também uma grande curiosidade e interesse pela nova sociedade. Por outro lado, o discurso de Page aponta o espaço doméstico como uma intrincada rede de relações que, em certa medida, representa um microcosmo do funcionamento da própria sociedade brasileira localizada na primeira metade do século XX.

\section{Referências}

DA MATTA, Roberto. A casa e a rua: espaço, cidadania, mulher e morte no Brasil. São Paulo: Brasiliense, 1985.

FELMAN, Shoshana; LAUB, Dori. Testimony. London: Routledge, 1992.

HOLANDA, Sergio Buarque de. O Homem Cordial. In: Raízes do Brasil. Rio de Janeiro: José Olympio, 1983 [1.ed. 1953].

LEJEUNE, Philippe. Le Pacte autobiographique. Paris: Seuil, 1986.

MARCUS, Laura. Autobiographical discourses: theory, criticism, practice. Manchester: Manchester University Press, 2006.

PAGE, Patricia Kathleen. Brazilian Journal. Toronto: Lester \& Orpen Dennys, 1987.

Recebido em abril de 2014.

Aceito em outubro de 2014. 